\title{
LÁMPARAS TARDOANTIGUAS DEL YACIMIENTO DE CERCADILLA. CÓRDOBA
}

\author{
$M^{a}$ del Camino FUERTES SANTOS
}

\section{Resumen}

Con este trabajo pretendemos dar a conocer un nuevo tipo cerámico, cuya función está claramente vinculada a la iluminación, recogido en Cercadilla. De este tipo se han recuperado en nuestro yacimiento hasta tres variantes, sin embargo conocemos una cuarta variable, que hemos considerado oportuno estudiarla e incluirla en esta tipología, aunque no está presente en Cercadilla, procedente del Museo Histórico Municipal de Villa del Río (Córdoba).

\section{Summary}

The intent of this paper is to make known a new ceramic form, recovered in Cercadilla, which function is clearly related to illumination. Up to three variations have been recovered of this kind at our site. However, a fourth variant has been made known to us, which we have considered appropriate to study within this typology -although it is not present in Cercadilla- originating from the Municipal Historic Museum of Villa del Río (Córdoba, Spain).

En este trabajo se presentan los tres únicos ejemplares de lámparas, aparecidos hasta el momento, pertenecientes a un nuevo tipo formal del yacimiento de Cercadilla. Nos encontramos ante piezas muy raras de las conocemos escasos datos sobre su procedencia, dispersión y cronología. Esta escasa presencia no sólo es sintomática de nuestro yacimiento sino que es un hecho característico en toda el área peninsular.

Con el estudio de los contextos estratigráficos en los que han aparecido hemos intentado ofrecer una cronología lo más ajustada posible a este tipo de recipientes e incluirlos dentro de nuestra tabla tipológica de piezas destinadas a la iluminación (forma 9 de Cercadilla). Esta tabla otorgaba un número correlativo a los diferentes 
tipos, según sus características formales y adscripción cronológica. Por ser piezas más antiguas a las estudiadas hasta el momento hemos creído oportuno denominar a este nuevo tipo con el número 0.

\section{Descripción formal de las piezas y de su contexto arqueológico}

\section{Tipo 0}

Son lámparas circulares, realizadas a torno, que poseen dos partes bien diferenciadas. Se levantan sobre un soporte, generalmente alto y macizo -aunque una de nuestras variantes se ha realizado sobre una especie de platito- de base plana, con paredes exvasadas y cóncavos en su parte superior. Desde el interior de este soporte se alza una chimenea de forma troncocónica, más o menos abierta en su base, según los casos, en la que se han realizado dos orificios: uno en la zona superior, destinado a la introducción del aceite, y otro en uno de sus laterales, en donde se localizaba la mecha y por donde se efectuaba la iluminación. Dos de los ejemplares conocidos poseen un asa, de pellizco. Los otros dos no se conservan completos por lo que desconocemos si la poseyeron'.

\section{Variante 1.- Cer 93, Sector18, Corte13, U.E.32, Bolsa 45 (Fig. 1, Lám. 1).}

Diámetro de base: $4,5 \mathrm{~cm}$

Diámetro del borde de la chimenea: $2,6 \mathrm{~cm}$.

Altura total de la pieza: $3,3 \mathrm{~cm}$.

Es la pieza peor conservada. De tamaño menor que sus homónimas. Su soporte es un pequeño plato de $0,5 \mathrm{~cm}$. de grosor, de paredes exvasadas que no conservan el borde. Del centro de ese plato se alza la chimenea, muy abierta en su base, con paredes reentrantes y borde redondeado, ligeramente engrosado. Realizada a torno con arcillas claras muy bien decantadas. Cocción oxidante ${ }^{2}$.

Esta pieza se localizaba en un sedimento arcilloso que cubría directamente a algunas de las estructuras murarias, ya saqueadas, que conformaban el tepidarium de las termas y a uno de los estratos de saqueo de las mismas.

\footnotetext{
' Durante el transcurso del año 1998 se llevó a cabo una excavación en la calle Magistral González Francés, de la que se recuperó un ejemplar de las mismas que las que aquí hemos estudiado. Este tipo se encuadraría dentro de la variante 1. Desde aquí queremos agradecer a Don Alberto Montejo Córdoba, director de esa axcavación, su amabilidad al permitirnos estudiar dicho ejemplar.

${ }^{2}$ La pieza localizada en Magistral González Francés es de idénticas características, diferenciándose, únicamente, en el borde. Mientras que el de la pieza de Cercadilla es redondeado y engrosado, el de Magistral González Francés es biselado al interior.
} 
Junto a esta lámpara se recuperaron numerosos elementos óseos y cerámicos. Dentro de este grupo cabe destacar la presencia, muy importante, de cerámica realizada a mano, con pastas muy groseras en las que abundan desgrasantes de tamaño medio y grueso. Algunas de las piezas presentan una cocción reductora, casi quemadas. Junto a un jarro/a de gran tamaño realizado a mano, de base muy ancha, cuerpo piriforme y boca trilobulada, se han recuperado varios fragmentos de ollas, una de ellas realizada a mano, con cuerpos globulares y bordes muy exvasados, redondeados o engrosados.

Variante 2.- Cer 96, Sector 1, Corte14, U.E. 44, Bolsa 283 (Fig. 1, Lám. 2).

Diámetro de base: $6 \mathrm{~cm}$.

Diámetro del borde soporte: $9 \mathrm{~cm}$.

Diámetro de borde de la chimenea: $2,8 \mathrm{~cm}$.

Altura total de la pieza: $3,6 \mathrm{~cm}$.

El soporte se realiza a partir de un recipiente de base plana, ligeramente convexa, paredes exvasadas de borde redondeado, algo biselado hacia el interior. Del centro de ese recipiente se alza una chimenea troncocónica, con la base muy abierta, de paredes reentrantes y borde redondeado, más ancho en la zona destinada al orificio lateral que en su lado contrario. En ambos orificios se conservan los restos del fuego. Realizado a torno con arcillas claras, en las que se observa una relativa abundancia de desgrasantes muy finos de cuarzo y mica moscovita y en menor proporción de desgrasantes de color rojo, probablemente cerámica triturada. Cocción oxidante. En uno de los laterales de las paredes de la base se localiza el asa; es un simple pellizco realizado sobre las arcillas blandas.

El sedimento del que se recogió esta pieza formaba parte de uno de los estratos de colmatación interna de la estructura del criptopórtico. Concretamente se trataba del derrumbe, de piedras y adobes, de un horno doméstico, que se había realizado reutilizando un paramento de época tardoantigua.

Se han recuperado varios bordes vueltos, ligeramente caídos, de jarros/as de cocción reductora, realizados a torno con arcillas decantadas y desgrasantes muy finos. Así mismo se han recogido dos bordes de ollas, ambas realizadas a torno con arcillas con pocos desgrasantes. Las paredes de estos recipientes son relativamente finas. Los bordes son diferentes en cada uno de los casos; el de una de ellas es exvasado y almendrado mientras que el otro es redondeado y algo engrosado.

Una tapadera algo cóncava en su base y borde redondeado, quemada, con escasos desgrasantes de tamaño medio (muy similar a la forma 7.8 de Reynolds, 1985, 256, fig. 8.40); un lebrillo de paredes exvasadas, borde redondeado y base plana, realiza- 
do a torno en pastas rojizas con abundantes desgrasantes de tamaño fino y grueso; un cuenco a torno, de arcillas claras bien decantadas, carenado en la zona cercana al borde -que es reentrante y redondeado- y un fragmento de cuello carenado con arranque de asa, a torno, del mismo tipo que los tipificados en el criptopórtico (FUERTES y GONZÁLEZ, 1996, 133, fig. 77) son los materiales que completaban el elenco cerámico que acompañaba a esta variante del tipo 0.

Variante 3.- Cer 94, Sector 12, Corte 117, U.E. 9, $3^{\text {a }}$ alzada, Bolsa 39 (Fig. 2, Lám. 3).

Diámetro de base: $5,3 \mathrm{~cm}$.

Diámetro conservado del borde del soporte: $9,1 \mathrm{~cm}$.

Diámetro de borde de la chimenea: $2,5 \mathrm{~cm}$.

Altura total de la pieza: $4,9 \mathrm{~cm}$.

El soporte es de base plana y paredes exvasadas con borde reentrante y labio biselado, ligeramente apuntado. Del centro del soporte se levanta la chimenea de $3,3 \mathrm{~cm}$. de altura, con la base menos abiertaque los ejemplares anteriormente descritos, de forma troncocónica con paredes reentrantes y borde redondeado. En el orifico lateral se conservan las huellas del fuego. Realizada a torno con arcillas rojizas poco decantadas con abundantes desgrasantes de tamaño medio y fino. Nervio de cocción. No conserva el asa.

Esta pieza se localizó en uno de los sedimentos de relleno y colmatación de una fosa realizada para verter los detritus constructivos -fragmentos de tegulae, ladrillos, restos de mampuesto, argamasa, etc.- derivados del saqueo de las estructuras tardorromanas. Concretamente, esa fosa se localizaba inmediatamente al Norte de los apartamentos imperiales, por lo que es lógico pensar que los restos formaran parte, originalmente, de alguno de los muros de ese edificio.

Los materiales asociados a este estrato están en su mayor parte realizados a torno. Destaca la presencia de cerámica de mesa con cubierta de engobe claro y pintada en color rojo o en color gris. Los esquemas pictóricos son abstractos, del mismo tipo que los aparecidos en las piezas recuperadas en el interior del criptopórtico y que se encuadraron en un marco temporal que abarcaba desde el siglo VI hasta los primeros años del siglo VIII (FUERTES y GONZÁLEZ, 1996, 135).

La cerámica de mesa se realiza con pastas claras y suele estar muy bien decantada. No ocurre lo mismo con la cerámica de cocina que aunque de buena factura presenta abundancia de desgrasantes. El grosor de las paredes de las ollas tiende al estrechamiento y todas son globulares con bordes exvasados y labios ligeramente caídos.

Se ha localizado una tapadera plana con el arranque de lo que sería una única asa que atravesaría la superficie de la pieza de un lado a otro, muy próximo al borde, que no se 
conserva. Toda la superficie de esta pieza ha sido decorada con incisiones realizadas a peine cruzadas unas con otras. Tapaderas de este tipo se han localizado en Cercadilla en el mismo contexto que las piezas de mesa pintadas con esquemas abstractos (vid. supra), al igual que en otros yacimientos peninsulares. Así por ejemplo es muy semejante a las aparecidas en Alcudia, Elche, fechadas en el siglo VII-VIII (REYNOLDS, 1985, 256, fig. 8; GUTIÉRREZ, 1993, 47, fig. 4; 1996, 95, fig. 29).

De este mismo contexto se ha recogido un borde exvasado de botella o redoma, de sección triangular, con doble moldura en el cuello; está realizada a torno con arcillas claras muy decantadas con desgrasantes muy finos.

Variante 4.- Museo Histórico Municipal de Villa del Río ${ }^{3}$ (Fig. 2, Lám. 4).

Diámetro de base: $5,2 \mathrm{~cm}$.

Diámetro del borde del soporte: $11 \mathrm{~cm}$.

Diámetro de borde de la chimenea: $3,3 \mathrm{~cm}$.

Altura total de la pieza: $4,1 \mathrm{~cm}$.

Realizada, al igual que las de Cercadilla, a torno, con arcillas claras bien decantadas. El soporte, de paredes exvasadas con borde redondeado es, en este caso, muy alto por lo que la chimenea, de paredes reentrantes e igualmente de borde redondeado, casi no sobresale por encima del mismo. Esta pieza también conserva el asa, que al igual que la localizada en nuestro yacimiento, es un simple pellizco. La particularidad es que en este caso, el asa, se localiza en el mismo lado que el orificio en el que se situaba la mecha. Gran parte del recipiente muestra huellas de fuego. Esta variante no está representada en Cercadilla.

La pieza se localizó al Norte del término municipal de Villa del Río, en una zona muy cercana al municipio de Montoro. Su descubrimiento, casual, se realizó durante el transcurso de la ejecución de labores agrícolas en un área de la que se tienen noticias de su ocupación en época romana y medieval (aunque al no haberse realizado ningún sondeo arqueológico en la zona se desconoce completamente la secuencia estratigráfica real de este yacimiento).

\section{Conclusiones}

El ámbito de dispersión de nuestras piezas se extiende por el área del Mediterráneo Oriental y el Norte de África. Se han localizado en Corinto donde fueron tipificadas por Broneer (BRONEER, 1930, 120, 122-124, Pl. XXIII-XXIV), que las encuadró

\footnotetext{
${ }^{3}$ Queremos agradecer a los responsables de este museo, y en especial a Dña. M $\mathrm{M}^{\mathrm{a}}$ Ángeles Clémentson, el habernos facilitado el estudio de la pieza aquí presentada.
} 
como Forma XXXV dentro del grupo de Lámparas Bizantinas (anteriormente, también en Grecia se habían dado a conocer otros ejemplares de este tipo, de los que no se aportaban datos ni sobre su procedencia ni sobre su cronología). Los ejemplares más antiguos, con la chimenea menos desarrollada y con el soporte más profundo, no presentaban ningún tratamiento exterior de las pastas, mientras que los más tardíos, que estuvieron en uso durante la dominación de Juan I Zimisces (969-976), poseían, en la mayoría de los casos, un vedrío en color melado o en color verde del mismo tipo que los utilizados en la cerámica propia del mundo islámico. En estos ejemplares la chimenea se elevaba considerablemente por encima del soporte.

Así mismo se han recuperado piezas en Chipre que Oziol (OZIOL, 1977, 287288, Pl. 48) las clasifica como Lámparas realizadas a Torno, en concreto dentro del Tipo 3, y las fecha en el siglo $\mathrm{X}$ (basándose en la datación otorgada a las piezas recuperadas en Corinto, aunque pone en duda el rigor de esa clasificación). No diferencia las lámparas completamente circulares (que poseen un pequeño pellizco, a modo de piquera, localizado en el mismo lugar donde se abre el orifico para la iluminación), de aquellas con el cuerpo trilobulado (seguramente mucho más tardías tal y como ya apuntaba Waagé -WAAGÉ, 1934, 68, fig. 81-). Exceptuando una de las lámparas presentadas, el resto poseen un asa que parte del soporte y se introduce en el interior de la chimenea. La cronología dada por la autora a las piezas no se fundamenta en criterios estratigráficos, sino que recoge las opiniones difundidas por otros investigadores que se dedicaron anteriormente al estudio de estas piezas.

Waagé, también localiza algunos ejemplares de este tipo en la zona Siria, concretamente en Antioquía, y los tipifica como Forma 57. Admite, al igual que Broneer que las piezas con la chimenea más baja son anteriores a áquellas que la tienen más alta. Las fecha entorno a los siglos VIII-IX ${ }^{4}$ (WAGÉE, 1934, 68, fig. 81). Menzel, siguiendo a Waagé, las considera árabes y cree que su área de influencia sería, igualmente, la zona de Siria (MENZEL, 1954, 102, Abb. 83).

Durante las excavaciones en Susa se recogieron algunos ejemplares, con características morfológicas muy similares a nuestras piezas, denominadas Lámparas Circulares o Tipo 1, encuadradas dentro del Nivel 3, fechado entre la primera mitad del siglo VI y la segunda mitad del siglo VIII (ROSEN-AYALON, 1974, 128, Pl. XXVIII).

Sin embargo las piezas mas cercanas, desde el punto de vista morfológico, a los ejemplares estudiados por nosotros son las recuperadas en el Norte de África e Italia.

\footnotetext{
${ }^{4}$ Waagé en la misma publicación presenta algunas formas con características morfológicas muy similares a las que aquí nos ocupan. Las diferencias más notorias radican en la forma del soporte, que en vez de ser circular es como el de un candil de pellizco. Este tipo lo fecha en momentos post-califales.
} 
En Sabratha (Libia) se documentaron varios ejemplares que Joly (JOLY, 1974, 58 y 205, Tav. LVIII-4) agrupa como Lámparas de los siglos VII-XIII d.C., concretamente en el grupo de Lucernas Varias. No da datos estratigráficos pero considera, aunque con ciertas dudas, que este tipo debe encuadrarse en un marco temporal que abarcaría los siglos XI-XII.

En Túnez es donde mayor número de ejemplares de esta forma se han recuperado, procedentes, la mayor parte de ellos de la ciudad de Uthina ${ }^{5}$. Se localizaron en un taller de cerámica que se había levantado sobre el arrasamiento realizado por los vándalos sobre las termas de esa ciudad. Su situación estratigráfica es la que llevó a los diferentes investigadores a encuadrar esta forma a mediados del siglo V, durante el momento de invasión del Norte de África por parte de las tropas vándalas (DELATTRE, 1890; DE CARDAILLAC, 1890, 321, fig. 87; 1922, 130, fig. 181; CAT. ALAOUI 1897, 153, Pl. XXXV, 49-50; LECLERQ, 1907, 517, fig. 347; LECLERQ y CABROL, 1928, 1100-1104, fig. 6586.22-24).

En el Atlante delle forme ceramique (ATLANTE, 1985, 205-206, tav. CIII- 5 a-b y CLXII- 3 a-c) se agrupa a este tipo dentro de la Forma XVI o Lucernas sin rostrum. Atlante recoge esta forma -de idénticas características morfológicas a las estudiadas por nosotros- porque el ejemplar cartaginés presentado posee un barniz opaco, similar al de la sigillata africana $\mathrm{D}^{1} \mathrm{e}$ indica que existen imitaciones de esta forma realizadas en cerámica común. Considera que su área de dispersión es la franja central del África Septentrional, es decir, Argelia, Túnez y Libia. No se pronuncia a la hora de adscribir esta forma a una cronología concreta, simplemente hace una recopilación de lo dicho con anterioridad por otros autores ${ }^{6}$.

\footnotetext{
${ }^{5}$ A pesar de que durante los primeros años de excavaciones en Uthina se recuperaron una gran cantidad de lámparas de este tipo nunca se realizó ninguna clasificación tipológica de las mismas.

${ }^{6}$ Existen una serie de lámparas que apuntan ciertas similitudes formales con las que nosotros estamos estudiando, aunque como ya apuntó en su momento Broneer, pertenecen a un tipo diferente (BRONEER, 1930; WAAGÉ, 1934; MENZEL, 1954, OZIOL, 1977). Se trata de igual manera de lámparas circulares sin desarrollo del rostrum o de la piquera pero no poseen chimenea, que se ha sustituido por un simple orificio en la zona central del margo. Estas piezas están muy decoradas en su parte superior, con motivos cristianos e incluso con inscripciones -existen de igual modo algunas piezas no decoradas (SZENTLÉLEKY, 1969, 131132; OZIOL, 1977, 286, Pl. 48). Se han localizado en Corinto, en donde se considera que son anteriores a las del tipo XXXV y se fechan durante la «época paleocristiana», sin más precisiones (BRONEER, 1930, 120, PI. XXIII), en Jerusalén fechadas entre los siglos VII-VIII, (BAGATTI, 1964), Siria o Palestina (KENNEDY, 1963), en Antioquía fechadas entre los siglos VI-VII (WAGÉE, 1941). Algunos ejemplares son recogidos por ROSENTHAL y SIVAN (1978, 141-142), que los encuadran dentro del grupo de Lámparas circulares en el capítulo de Lámparas bizantinas e islámicas procedentes del Este, sin embargo no conocen con certeza la procedencia de dichos ejemplares por lo que no se aventuran a darles una fecha concreta.
} 
En Italia, en concreto en el Sudeste de la Puglia, aparece, igualmente este tipo, fechado en el siglo VII, asociado al complejo de hornos de Otranto (ARTHUR y PATTERSON, 1998, 521-522, fig. 8.11).

En el museo de Jaén también existen algunos ejemplares que nos recuerdan, en cierta medida, a las lámparas cordobesas, ya que al igual que éstas son circulares y carecen de piquera, si bien formalmente se corresponderían con un tipo diferente al nuestro. Estas piezas fueron clasificadas como Lámparas cerradas (BAZZANA y MONTMESSIN, 1985, 13, 52-53). Una de las piezas ( $\mathrm{n}^{\circ}$ inv. 070, procedente de Andújar) posee una chimenea desarrollada en altura y dos orificios en el depósito, por donde se efectuaría la iluminación; este ejemplar no está fechado. Los otros dos ( $\mathrm{n}^{\circ}$ inv. 068,069 ) son fechados en el siglo XI, y fueron encontrados en un barco árabe hundido cerca de las costas francesas.

La situación estratigráfica en la que se localizan las lámparas del tipo 0 de Cercadilla es la que nos permite asociar estas piezas a un momento determinado de la historia. Se localizaron en contextos de saqueo y derrumbe de las estructura romanas o por encima de los mismos. La cerámica asociada a esos niveles nos indica que nos encontramos en momentos posteriores a la ocupación tardorromana del edificio y anteriores al uso islámico del yacimiento.

Como fecha post-quem hemos tenido en cuenta el registro estratigráfico anterior a los contextos aquí analizados y de los que hemos recuperado las diferentes variables del tipo 0 , aunque en dos de los casos ello no ha sido posible por encontrarse uno de esos contextos sobre el terreno geológico del yacimiento (variante 3 ) y el otro por localizarse sobre estratos y estructuras no excavadas hasta el momento (variante 2).

Por el contrario sí contamos con un momento post-quem para la variante 1 . Como ya comentábamos más arriba este ejemplar apareció en un estrato de época tardoantigua que se superponía a los niveles de saqueo de las termas (HIDALGO, 1996, 81). En uno de esos niveles se realizó un enterramiento infantil en cista de tegulae en la que no se depositó ningún ajuar. La utilización de las tegulae para la construcción de la cista nos indica la pervivencia de la tradición romana; ello permite la datación de este enterramiento entre los siglos VI-VII. Además, en este nivel de saqueo destaca la presencia de un fragmento de sigillata africana $\mathrm{D}^{2}$ de la forma Hayes 104 . La cronología de esta forma abarca desde un momento impreciso de la primera mitad del siglo VI hasta el año 580 d.C. (HAYES, 1972, 166; TORTORELLA, 1987, 306).

Así mismo podemos asegurar que no nos encontramos en momentos claramente islámicos ya que de momentos emirales contamos en Cercadilla con una serie de formas claves, características de los siglos VIII-IX, y que no están presentes en ninguno de los tres contextos estudiados. Hemos observado en concreto: 
- Ausencia total del tipo de jarrito/a del tipo 2.1b (FUERTES y GONZÁLEZ, 1994, $280 ; 1996,124)$ es decir jarros/as de boca circular -pintados o no- de bordes rectos o ligeramente reentrantes (escasas piezas aparecen con bordes exvasados), bordes redondeados o reentrantes de sección triangular, cuerpos globulares y bases planas, a veces ligeramente convexas (FUERTES y GONZÁLEZ 1993, 778, lám. 3.VI-XI; 1994, 294, fig. 3.1-8; 1996, 151, fig. 87.2471)

- Escasez cuantitativa de la forma 1 -ollas-, muy abundante durante el período emiral.

- Escasez cuantitativa de la forma 2 -jarros/as-. Este grupo formal se caracteriza por ser el más abundante, no solamente durante el emirato sino también en las fases posteriores, sin embargo su presencia es mucho más escasa en momentos previos a la dominación islámica.

- Ausencia total de cerámica pintada con esquemas profilácticos atravesando las piezas tanto longitudinal como transversalmente (FUERTES y GONZÁLEZ 1993, 777778; 1994, passim; 1996, passim).

- Ausencia total de tapaderas del tipo 4, es decir de base plana con los bordes vueltos hacia arriba, formas muy comunes durante la fase emiral (FUERTES y GONZÁLEZ, 1993, 778, lám. 3.I-II-IV; 1994, 298, fig. 7.1-2; 1996, 150).

- Ausencia total de la forma candil. Esta forma está presente desde los primeros momentos de la dominación islámica (FUERTES y GONZÁLEZ, 1993, 777; 1996, passim; FUERTES, 1997 e.p.)

Por tanto y teniendo en cuenta nuestros propios datos estratigráficos, consideramos que el tipo 0, en Cercadilla, se encuadraría entre los últimos momentos del siglo VI y fundamentalmente durante el siglo VII ${ }^{7}$. No tenemos datos suficientes como para pensar que este tipo se fabricase en un taller cordobés, sin embargo si eso fuera así es probable que nos encontrásemos ante producciones locales que imitarían formas venidas de fuera, seguramente desde el Norte de África. En contra de lo que ocurre en otras zonas del Mediterráneo o del Próximo Oriente y en el estado actual de la investigación, este tipo no parece haber evolucionado en momentos más tardíos, tal vez debido a una asimilación muy rápida de la forma candil que desplazaría desde los primeros momentos a estas lámparas.

\footnotetext{
${ }^{7} \mathrm{Al}$ no contar con un número suficientemente relevante de estas piezas nos parece aventurado intentar realizar una evolución tipológica de las mismas. Es probable, sin embargo, que, y siguiendo Broneer y Waagé podamos observar esa evolución en el desarrollo formal de las chimeneas. De esta manera las piezas más antiguas serían aquéllas que tuvieran las bases de las chimeneas muy abiertas y estuvieran menos desarrolladas en altura (coincidirian con las variantes 0 y 1). Aquellos ejemplares que tuvieran las chimeneas con las bases más cerradas y más elevadas sobre el soporte serían piezas algo más tardías (variantes 3 y 4). Esperamos que en futuras excavaciones salgan a la luz nuevos ejemplares de este tipo que nos permitan ratificar estos datos.
} 


\section{BIBLIOGRAFÍA}

ARTHUR, P. y PATTERSON, H. (1998): «Local pottery in Southern Puglia in the sixth and seventh centuries», en SAGUI, L. (ed.): Ceramica in Italia: VI-VII secolo. Firenze.

ATLANTE (1985): Atlante delle forme ceramique I. Ceramica fine romana nel bacino mediterraneo (medio e tardo impero). EAA. Roma.

BAZZANA, A; MONTMESSIN, Y. (1985): La céramique islamique du Musée Archéologique de Jaen (Espagne). París.

BAGATTI, B. (1964): «Lucerne fittili di Palestina dei secoli VII-VIII». Rivista di Archaeologia Cristiana 40, 253-269.

BERTHIER, A (1943): Les vestiges du christianisme antique dans la Numidie centrale. Argelia.

BRONEER, O. (1930): Corinth. Results of Excavations, IV.2. Terracota Lamps. Cambridge.

CAT. ALAOUI (1897): Catalogue du Musée Alaoui. París.

DE CARDAILLAC, F. (1890): «Histoire de la lampe antique en Afrique». Bulletin de la Société de Géographie et d'Archéologie de la province d'Oran X, 241 ss.

DE CARDAILLAC, F. (1922): Des quelques lampes antiques découvertes dans l'Afrique du Nord. Tarbes.

DELATTRE, A.L. (1890): Lampes chrétiennes de Carthage. Lille.

DELATTRE, A.L. (1891): «Lampes chretiénnes de Carthage». Rev. Art. Chrét. XXXIV, 39 ss.

GUTIERREZ, S. (1993): «La cerámica paleoandalusí del sureste peninsular (Tudmir): producción y distribución». La cerámica altomedieval el Sur de Al-Andalus, 37-65.

GUTIÉRREZ, S. (1996): La cora de Tudmir. De la antigüedad tardía al mundo islámico. Poblamiento y cultura material. Madrid-Alicante.

FUERTES, Ma C. (1995): "Un conjunto cerámico post-califal del yacimiento de Cercadilla. Córdoba". Anales de Arqueología Cordobesa 6, 265-291.

FUERTES, Ma C. (1997): "La ocupación medieval del yacimiento de Cercadilla, Córdoba. Una casa califal". Almirez 6 (Centro asociado de la U.N.E.D.), 161-181.

FUERTES, $M^{\text {a }}$ C. (1997 e.p): «La evolución de la cerámica medieval de Cercadilla. Estado de la cuestión». I Jornadas de Arqueología Cordobesa. Córdoba. 
FUERTES, Mª C; GONZÁLEZ, M. (1994 a): “Avance al estudio tipológico de la cerámica medieval del yacimiento de Cercadilla, Córdoba. Materiales emirales". IV Congreso de Arqueología Medieval Española, T.III, Alicante, 771-778.

FUERTES, Ma C; GONZÁLEZ, M. (1994 b): "Nuevos materiales cerámicos emirales de Cercadilla (Córdoba): Ensayo tipológico". Anales de Arqueología Cordobesa 5, 277-301.

FUERTES, Ma C; GONZÁLEZ, M. (1996): "Materiales de época medieval" en HIDALGO et alii, El criptopórtico de Cercadilla. Análisis Arquitectónico y secuencia estratigráfica, Sevilla, 119-185.

HAYES, J.W. (1972): Late Roman pottery. Londres.

HIDALGO, R. (1996): Espacio público y espacio privado en el conjunto palatino de Cercadilla (Córdoba): El aula central y las termas. Sevilla.

HIDALGO, R; ALARCON, F; FUERTES, Mª C; GONZÁLEZ, M; MORENO, M. (1996): El Criptopórtico de Cercadilla. Análisis arquitectónico y secuencia estratigráfica. Sevilla.

LASSUS, J. (1956): «Fouilles à Mila, Campagne préliminaire (juin-juillet 1957)», Libyca IV, pág. 199 ss. fig. 36.

.LASSUS, J. (1958): «L'archeologie algérienne en 1957 (Tiddis)». Libyca VI, 251 ss. 20 , table IV $\mathrm{n}^{\circ} 20$.

LECLERQ, H. (1907): Manuel d'archéologie chrétienne depuis les origines jusqu'au VIII siècle, I-II. París.

LECLERQ, H; CABROL, F. (1928): Dictionnaire d'archéologie chrétienne et de liturgie, VIII, I. París.

JOLY, E. (1974): Lucerne del Museo di Sabratha. Roma.

KENNEDY, C.A. (1963): «The Devolopment of the Lamp in Palestine», Berytus XIV. Fasc.II, 67-115.

MENZEL, H. (1969): Antike Lampen im römisch-germanischen Zentralmuseum zu Mainz. Mainz.

OZIOL, T. (1977): Salamine de Chypre. VII. Les Lampes du Musée de Chypre. París.

REYNOLDS, P. (1985): «Cerámica tardorromana modelada a mano de carácter local, regional y de importación en la provincia de Alicante». Lucentum IV, 245-266.

ROSEN-AYALON, M. (1974): Mémoires de la Délègation Archéologique en Iran. T.I. Mision Susiene. La Poterie Islamique. París. 
ROSENTHAL, R; SIVAN, R. (1978): Ancient lamps in the Scholoessinger collection. Jerusalén.

SZENTLÉLEKY, T. (1969): Ancient Lamps. Amsterdam.

TORTORELLA, S. (1987); «La ceramica africana: un riesame della problematica». Cerámiques hellénistiques et romaines II. París, 279-237.

WAAGÉ, F.O. (1934): Antioch-on-the-Orontes, Vol. I. Princeton.

WAAGÉ, F.O. (1941): Antioch-on-the-Orontes, Vol. III. Princeton. 

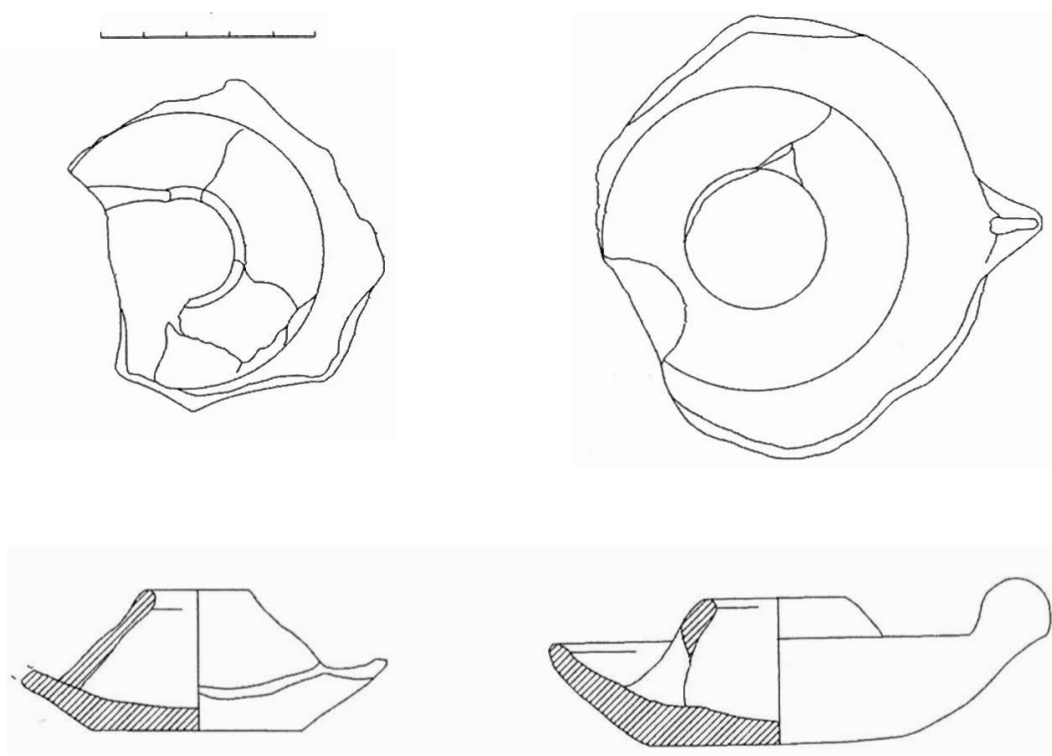

Fig. 1.- Variantes 1 y 2 del tipo 0.
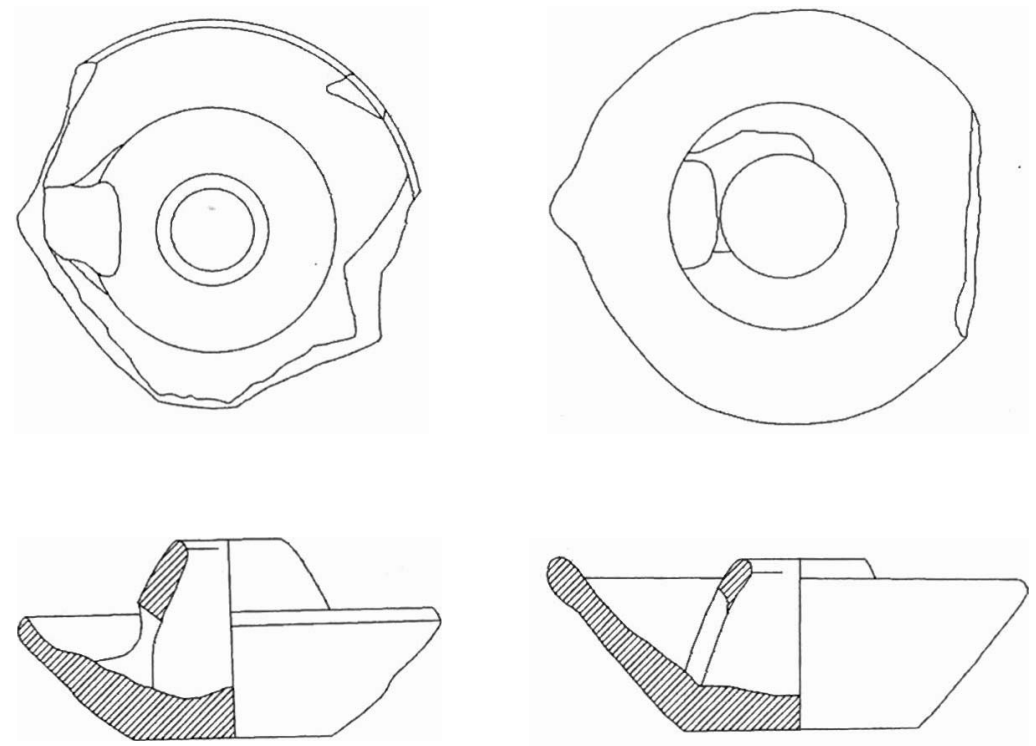

Fig. 2.- Variantes 3 y 4 del tipo 0. 


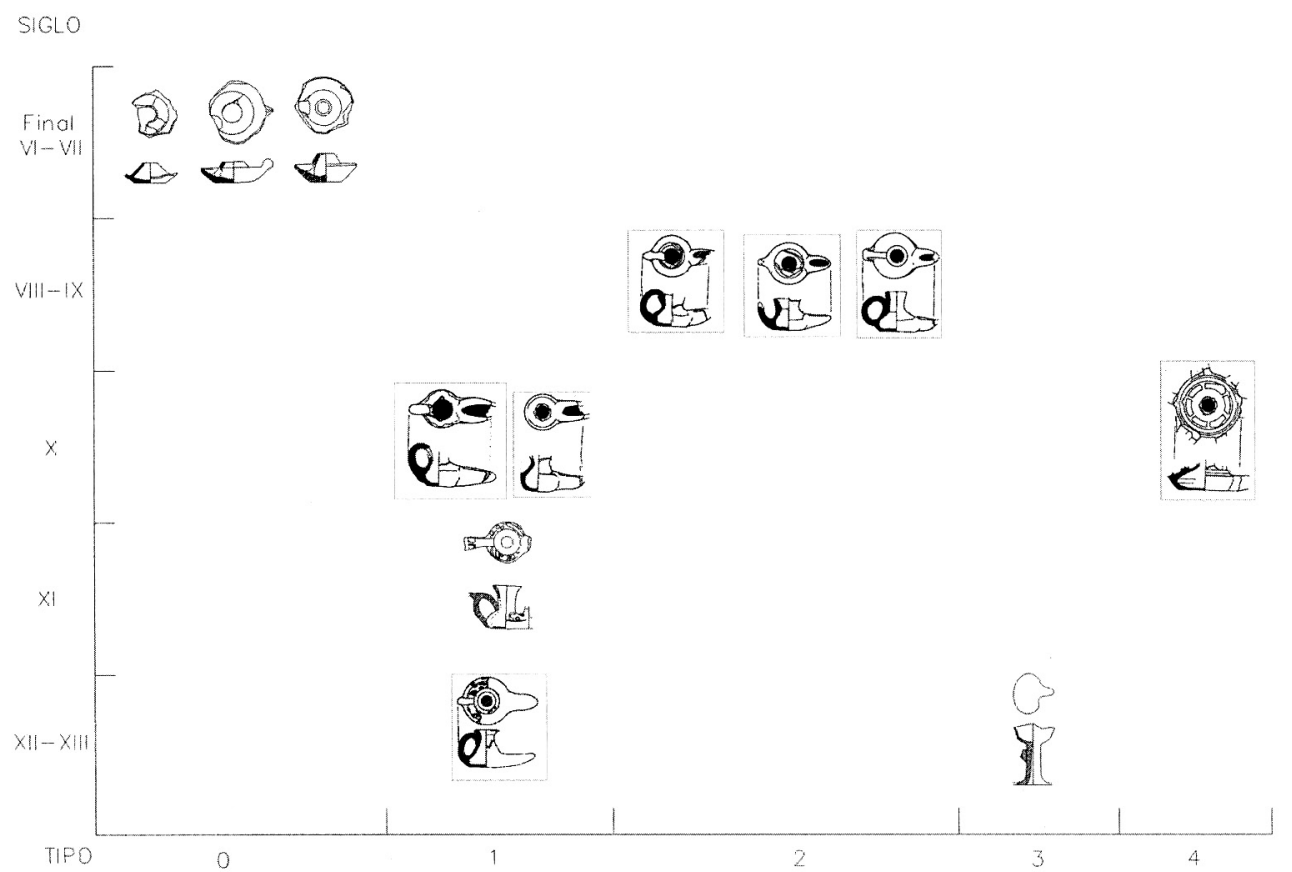

Fig. 3.- Tabla tipológica de la forma 9 de Cercadilla.

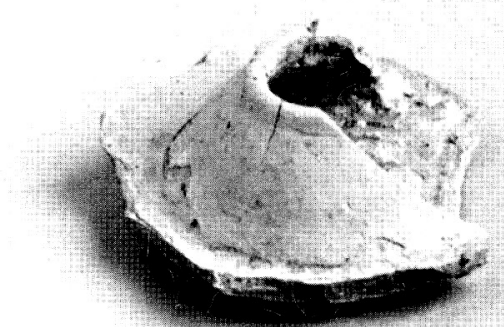

Lám. 1.- Variante 1 del tipo 0.

--- Grupo de investigación P.A.I. HUM 236 | http://www.arqueocordoba.com/publ/anales.htm --344 


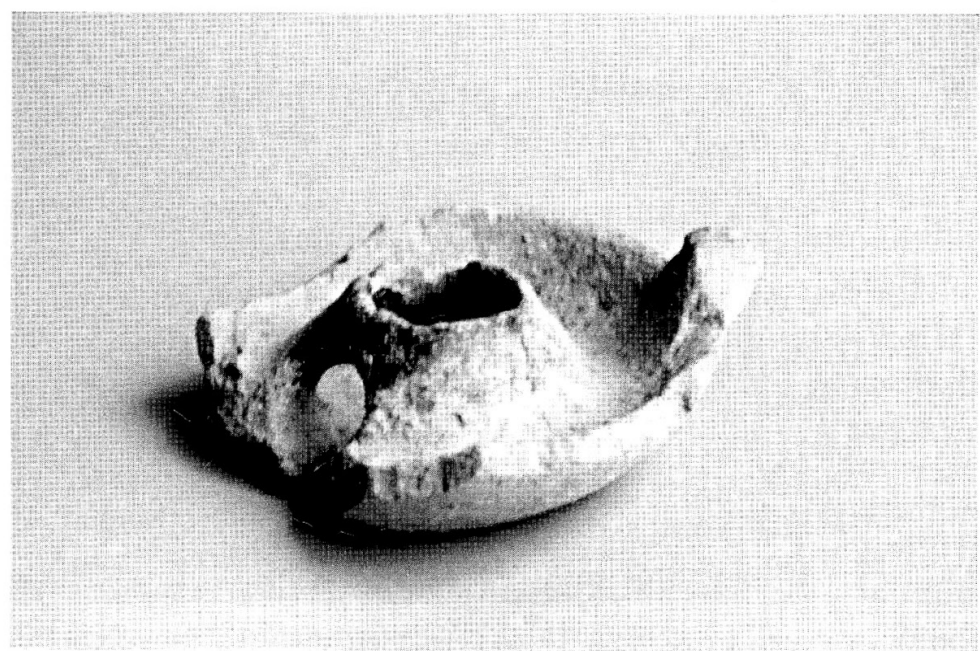

Lám. 2.- Variante 2 del tipo 0.

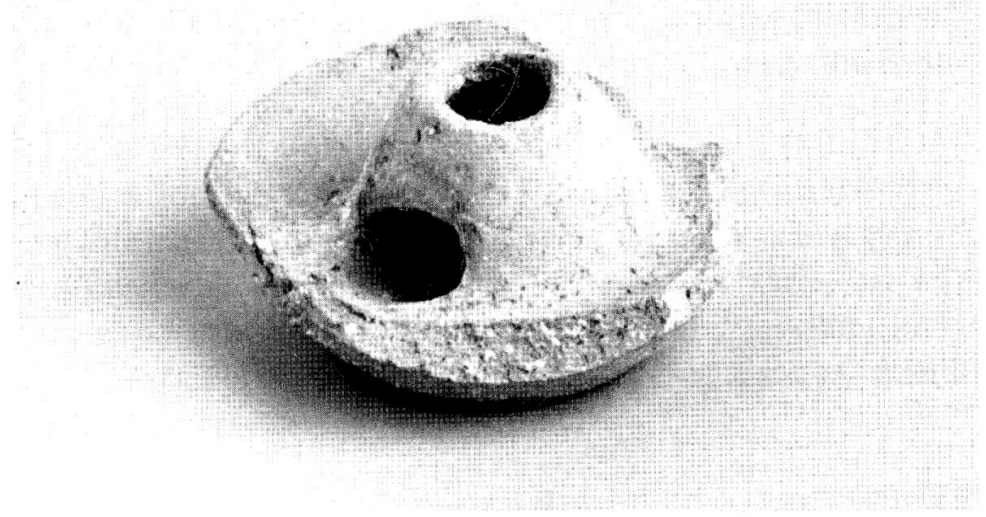

Lám. 3.- Variante 3 del tipo 0. 


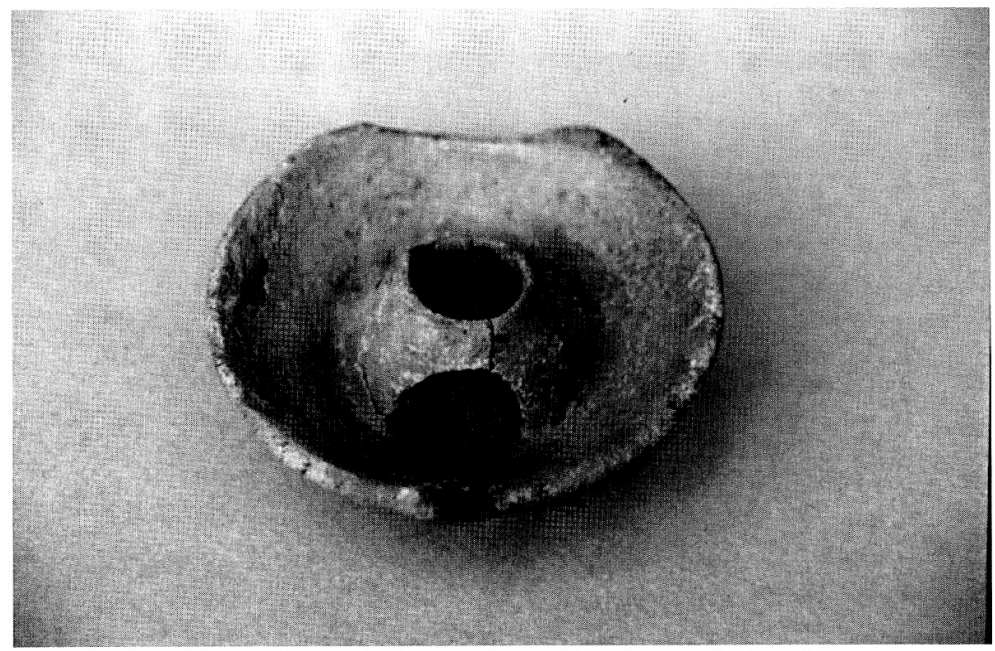

Lám. 4.- Variante 4 del tipo 0. Museo Histórico Municipal de Villa del Río. Córdoba. 